\title{
Planning and Shared Decision Making in Elderly Care
}

\author{
Eugene Yong Jun Tay ${ }^{\mathrm{a},{ }^{*}}$; Sebastiano Massaro ${ }^{\mathrm{b}}$
}

${ }^{\mathrm{a}}$ University of Warwick, United Kingdom.

${ }^{\mathrm{b}}$ University of Surrey, United Kingdom.

(*) Corresponding Author: University of Warwick, Warwick Business School - Behavioral Science, Scarman Road CV4 7AL Coventry, United Kingdom. E-mail: Eugene.tay.15@mail.wbs.ac.uk

Manuscript Version: August, 2018

This work is licensed under the Creative Commons Attribution 4.0 International License. To view a copy of this license, visit http://creativecommons.org/licenses/by/4.0/ or send a letter to Creative Commons, PO Box 1866, Mountain View, CA 94042, USA. 


\section{Which?}

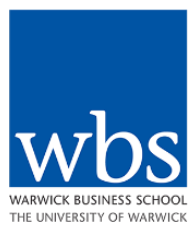

Planning and

Shared

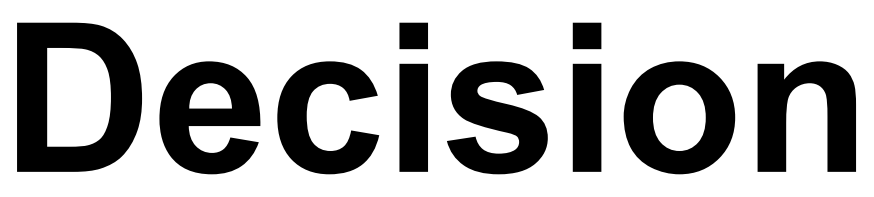

Making in

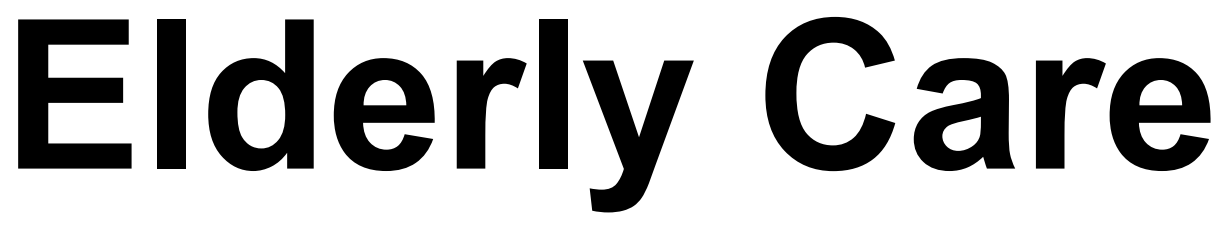

Research Review

2 Sebastiano Massaro 


\section{Contents}

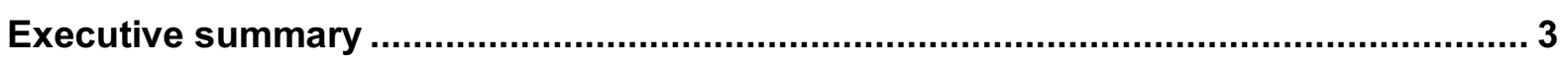

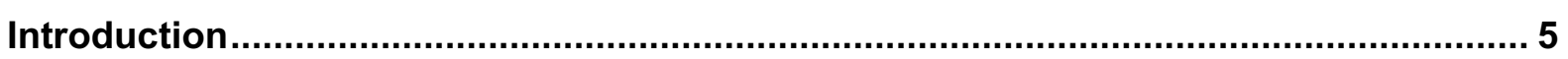

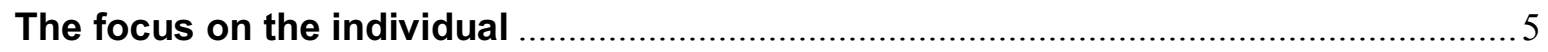

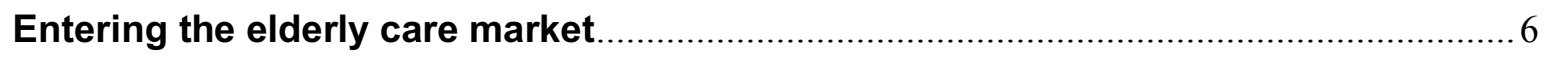

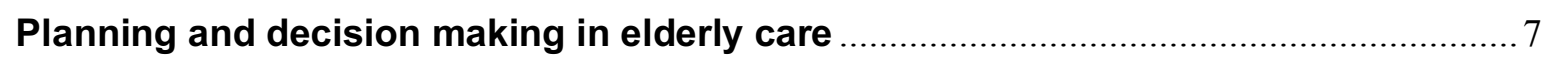

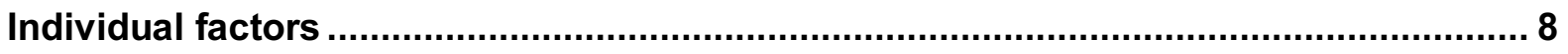

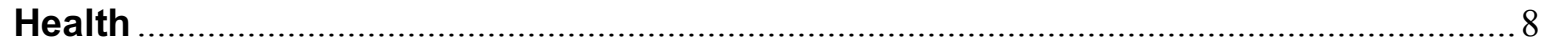

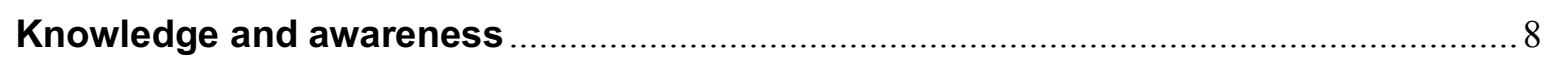

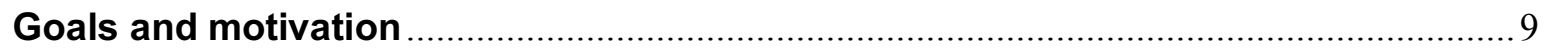

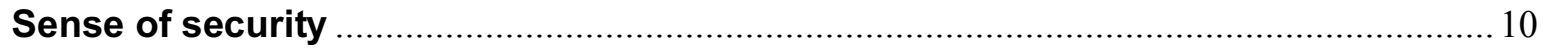

Task and contextual factors.............................................................................. 11

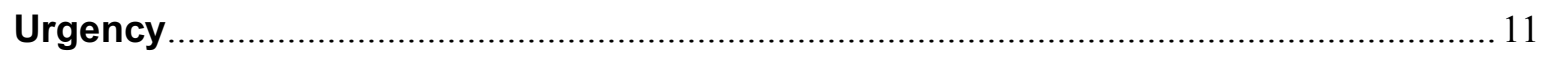

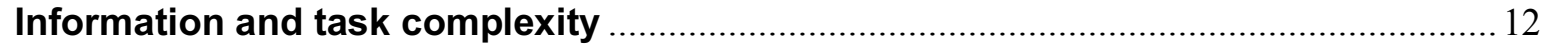

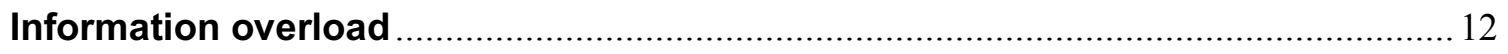

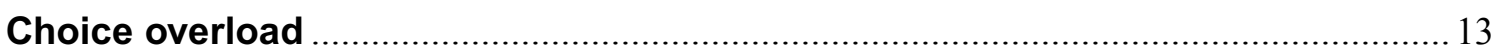

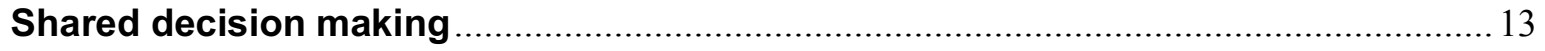

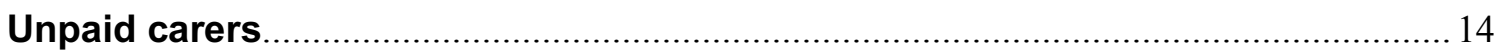

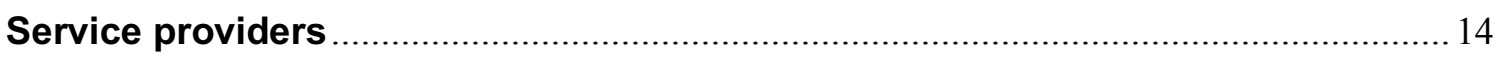

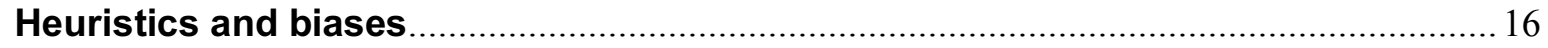

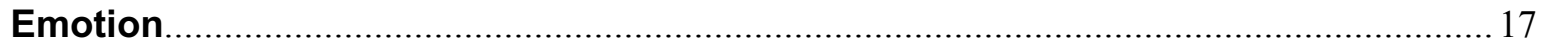

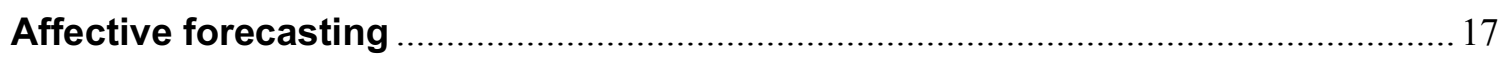

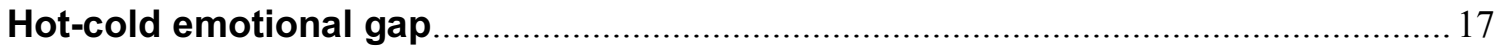

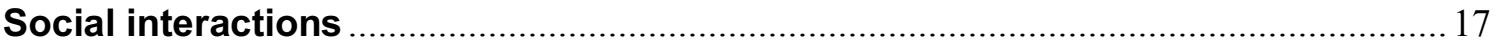

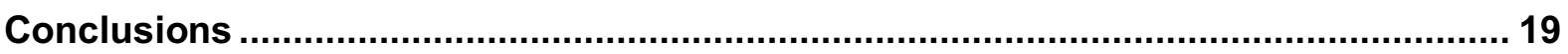

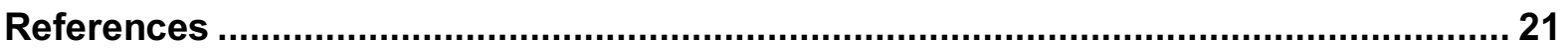




\section{Executive summary}

Decision making in elderly care is complex and multifaceted. No one can accurately predict whether they will have care needs or what these may be later in life. But if they do find they need it, most will learn that, unlike health care, they have to manage many of these needs themselves in often challenging circumstances.

The benefits of enhancing autonomy and choice in elderly care must be weighed against the risks of consumers making unsuitable choices without support, often in stressful circumstances. How can we best implement a consumer-oriented or person-centered social care system without compromising the needs and health of the population? The answer lies largely in how people plan and make good decisions about elderly care, as well as how others (e.g., policymakers and providers) can help them in these.

In line with other publications in this area (e.g., the Behavioural Insights Team), we regard good decisions as generally those:

- Which are made under relatively little time pressure or emotional stress;

- Which use accurate information about elderly care services; and

- Which incorporate consumers' needs and preferences.

Evidence suggests that decisions can often be taken in response to unplanned crises, where individual abilities may matter more in effective decision making (e.g., emotion regulation; stress management). However, these alone are unlikely to produce good decisions if consumers fail to possess accurate knowledge and understanding over what it is they want from their care and what their available options are.

Thus, the aim of this report is to use predominantly academic literature to highlight key cognitive, emotional and situational variables that influence decision making and planning in the context of elderly care. However, throughout our review, we found a consistent lack of academic literature related to these areas. Where this was the case, we usually supplemented our findings with publicly available publications, from both governmental and non-governmental agencies (e.g., charities). In addition, we emphasised the importance of planning in our report as early engagement is likely to bring more informed and person-centered decisions.

Our review identifies three overarching themes, each containing a subset of several factors that may serve as barriers or facilitators of decision making in elderly care:

1. Individual factors.

2. Task and contextual factors.

3. Cognitive and emotional factors. 
Overall, we find that stakeholders in elderly care (e.g., policymakers; service providers; family members) can vastly improve the quality of consumers' decisions by addressing these five main areas:

- Preferences. People rarely possess clear, coherent and stable preferences. Moreover, asking consumers to envision these in a future state of health and physical decline can be challenging for them. Learning from others' experience (e.g., reviews; personal stories) can be a good way for consumers to understand what it is they want and how best to get them.

- Awareness. Evidence suggests that there is generally poor consumer awareness and knowledge on what entitlements are available to people in the social care market. Consumers will benefit vastly from having more clarification and education on these issues.

- Information and choice. There is information, but limited choice in the social care sector. While poor ease of accessibility and comprehension usually hinder informed decision making, limited availability, geographical constraints, and high costs usually mean consumers have little or no choice in the first instance. Interested parties can redesign interfaces to facilitate consumer understanding (e.g., using simple layout and description) and decision making (e.g., tools for comparing multiple options), as well as improve the number of choices available to them.

- Network support. Many complex plans and decisions are made possible with the help of both formal and informal carers as well as local authorities. Our review indicates that how these parties participate and contribute to good decisions is relatively under researched.

- Stigma. Related to the first point on preferences is the common negative experience that ageing, or at least thinking about growing old and frail, triggers in people. Reframing ageing as a natural and common process, in addition to presenting choices or information about later life in a more positive way, can help alleviate fear and uncertainty. 


\section{Introduction}

People generally differ in when and why they enter the elderly care market in search of potential products and services. While some claim to be more risk averse and avid planners (Lusardi and Mitchelli, 2007), many others tend to react in response to a triggering event, such as a fall or the passing of a close one (Which?, 2018). In most cases however, early preparation and engagement with the care system can help individuals receive the care they want and avoid unnecessary stress, especially before the onset of a crisis or a significant health decline (Detering et al., 2010; Mullick, Martin and Sallnow, 2013).

Despite this, most consumers who do develop care needs often fail to plan and decide on a range of matters earlier in their lives. A survey in 2017 suggested that about 47 percent of the population wrongly think that social care is free at the point of need and only 35 percent had made financial plans for their future care (Ipsos MORI, 2017). Others prefer to avoid and only consider their potential care when the need arises (Behavioural Insights Team, 2017). Unfortunately, research also shows that this often comes at a time of crisis, where people struggle with information, time pressure and stress to make a rational decision (Behavioural Insights Team, 2017; Which?, 2018).

Planning and decision making for potential care is complex and challenging, involving individual, contextual and relational issues. To appreciate their importance in consumer decision making, we must first understand the role which individual consumers are expected to play in social care.

\section{The focus on the individual}

The 2014 Care Act sought to replace a 'one size fits all' approach with a 'person-centered' care system that today focuses on individuals' needs and wellbeing (Department of health and social care, 2014). Among other changes, the 2014 Care Act affects care consumers in three major ways:

1. Person-centered and responsive care. Intended to enhance autonomy and empower people to choose care services based on what they need, how they can best be cared for, and what they want. Care services ought to accommodate individuals' needs and preferences as well.

2. Decentralized the provision of social care to local authorities. Local authorities must now provide comprehensive information, manage a portfolio of sustainable high-quality care support services, and help personalise plans for residents requiring such services.

3. Prevention focus. It promotes a preventive approach to social care, rather than a reactive one, with a focus on improving people's independence and wellbeing before they need ongoing care and support. To that end, both public officials and consumers should see planning as a crucial approach in social care.

While these changes are thought to bring about more desirable outcomes, public satisfaction in social care remains significantly low and has been on a steady decline since 2012 (NHS, 2017). The 
proportion of respondents claiming to be "very" and "quite" satisfied in the Adult Social Care Survey (ASCS) fell from 30 percent in 2012 to 23 percent in 2017 (NHS, 2017). Furthermore, confusion over health and social care, complexity of navigating through information and choice as well as having to cope with emotion and uncertainty, often mars planning for future care needs (Behavioural Insights Team, 2017; Which?, 2018).

Importantly, these issues can prevent consumers from making good decisions, which we generally define as those:

- Which are made under relatively little time pressure or emotional stress;

- Which use accurate information about elderly care services; and

- Which incorporate consumers' needs and preferences.

Evidence suggests that when responding to unplanned crises, individual abilities (e.g., emotion regulation; stress management) may matter more in effective decision making than simply having more information (Mata and Nunes, 2010; Mata et al., 2012). Still, such innate qualities are unlikely to produce good decisions if consumers do not first possess accurate knowledge over what it is they want or the care options they have. As such, the report focuses on the general decision making landscape and how interventions can improve early planning, rather than identifying the traits that make certain consumer groups more adept in health crises.

\section{Entering the elderly care market}

Good care decisions, and by extension planning (in order to minimise time pressure or emotional stress), also depends heavily on individuals' circumstances, which varies from person to person. Based on interviews and focus groups with current care users, researchers at Which? (2018) identify four main entry points into the elderly care market:

1. Need to make changes to maintain independence. Individuals who fear or suffer from minor mobility issues or spells of loneliness may want to make home adaptations to improve reablement (e.g., handrails; ramps) and reduce the risks of an accident. They may also engage others to help with these (e.g., cleaner; community support).

2. Can no longer live independently without help. Individuals with major mobility issues may require assistance with basic needs, such as showering and cooking. Concerned friends and family members may notice this need and engage help earlier than the main recipient would otherwise.

3. Daily visits to provide support are no longer sufficient. At this point, a live-in carer or someone close may move in to support and meet the needs of the individual, or an individual may move into residential care. Choices are more limited at this point.

4. Crisis points. Unplanned, urgent emergencies involving consequential outcomes are usually the most complex and challenging routes into the social care system. An appropriate choice usually depends on a person's health condition, knowledge of future needs and preferences, availability of care options (e.g., specialist care; moving in with friends or family), as well as having sufficient funding. The individual is also subject to significant stress and uncertainty in such urgent scenarios, where information and choices are rarely considered in full. 
Individuals who plan and prepare earlier for their potential entry to the elderly care market, especially before the onset of a crisis, may be likely to have more choices, clarity and say over what they feel is best for themselves (Which?, 2018). In the following sections of this report, we consider various factors that impede or motivate early planning of care needs.

\section{Planning and decision making in elderly care}

We performed a literature review on the barriers, facilitators, and events that motivate early decision making in elderly care. Table 1 summarises three overarching themes associated with individual, task and contextual, as well as cognitive and emotional factors. Each theme consists of a subset of factors which, depending on the situation, may act as barriers or facilitators in planning for future care needs. We explain each of these in the following chapters.

Table 1. Themes and factors that influence planning and decision making in elderly care

\begin{tabular}{|c|c|c|c|c|}
\hline Themes & Main Factors & Factors as barriers & $\begin{array}{l}\text { Factors as } \\
\text { facilitators }\end{array}$ & Triggering events \\
\hline \multirow[t]{4}{*}{$\begin{array}{l}\text { Individual } \\
\text { Factors }\end{array}$} & Health & $\begin{array}{l}\text { Both good and bad } \\
\text { health }\end{array}$ & $\begin{array}{l}\text { Both good and bad } \\
\text { health }\end{array}$ & $\begin{array}{l}\text { Personal accidents; sudden onset } \\
\text { of illnesses; increasing frailty }\end{array}$ \\
\hline & $\begin{array}{l}\text { Knowledge and } \\
\text { awareness }\end{array}$ & $\begin{array}{l}\text { Poor knowledge and } \\
\text { unawareness }\end{array}$ & $\begin{array}{l}\text { Knowledgeable and } \\
\text { aware }\end{array}$ & $\begin{array}{l}\text { Awareness programs and } \\
\text { campaigns; experience with an } \\
\text { elderly relative or friend }\end{array}$ \\
\hline & $\begin{array}{l}\text { Goals and } \\
\text { motivation }\end{array}$ & $\begin{array}{l}\text { Poor goal clarity and } \\
\text { motivation }\end{array}$ & $\begin{array}{l}\text { Clear goal clarity and } \\
\text { motivated }\end{array}$ & $\begin{array}{l}\text { Awareness programs and } \\
\text { campaigns }\end{array}$ \\
\hline & $\begin{array}{l}\text { Sense of } \\
\text { security }\end{array}$ & High sense of security & Low sense of security & $\begin{array}{l}\text { Passing of a close one; poor } \\
\text { economic climate }\end{array}$ \\
\hline \multirow{4}{*}{$\begin{array}{l}\text { Task and } \\
\text { Contextual } \\
\text { Factors }\end{array}$} & Familiarity & New and unfamiliar & Familiar and routine & $\begin{array}{l}\text { Learning new technologies or } \\
\text { tasks }\end{array}$ \\
\hline & Time pressure & $\begin{array}{l}\text { Urgent and } \\
\text { consequential; high } \\
\text { discount rates }\end{array}$ & $\begin{array}{l}\text { Low time pressure; low } \\
\text { discount rates }\end{array}$ & Crises events \\
\hline & $\begin{array}{l}\text { Information and } \\
\text { task complexity }\end{array}$ & $\begin{array}{l}\text { Complex information; } \\
\text { information and } \\
\text { choice overload }\end{array}$ & $\begin{array}{l}\text { Comprehensible } \\
\text { information; reasonable } \\
\text { amount of information } \\
\text { and choice }\end{array}$ & $\begin{array}{l}\text { Presentation and ease of use that } \\
\text { maximises comprehension and } \\
\text { facilitates decision making }\end{array}$ \\
\hline & $\begin{array}{l}\text { Shared decision } \\
\text { making }\end{array}$ & $\begin{array}{l}\text { Contribute to false } \\
\text { sense of security }\end{array}$ & $\begin{array}{l}\text { Provide functional and } \\
\text { relational support }\end{array}$ & Suggestion from a GP or friend \\
\hline \multirow[t]{2}{*}{$\begin{array}{l}\text { Cognitive and } \\
\text { emotional } \\
\text { factors }\end{array}$} & $\begin{array}{l}\text { Heuristics and } \\
\text { biases }\end{array}$ & $\begin{array}{l}\text { Optimism, } \\
\text { discounting, } \\
\text { availability bias }\end{array}$ & $\begin{array}{l}\text { Adaptive decision } \\
\text { making }\end{array}$ & \\
\hline & Emotion & $\begin{array}{l}\text { Stress, anxiety, and } \\
\text { pain/discomfort }\end{array}$ & Relaxed and calm & $\begin{array}{l}\text { Sudden feelings of loneliness; } \\
\text { crises; 'hot-state' emotions }{ }^{1} \text { (e.g., } \\
\text { anger; anxiety; fear) }\end{array}$ \\
\hline
\end{tabular}

\footnotetext{
${ }^{1}$ Visceral forces, such as intense pain, discomfort and fear, can trigger a "hot-state" in individuals. It can motivate individuals to take remedial actions and/or bias judgment in decision making (e.g., making excessive living rearrangements after a personal accident).
} 


\section{Individual factors}

As a result of the recent changes to the social care system, individuals are expected to play an increasingly active role when it comes to planning and deciding a range of matters in elderly care.

Individuals are usually - though not always - in the best position to determine for themselves what they want and how best they can be cared for, in an ideal market/transaction environment. As such, individual differences in characteristics and conditions play a significant role in their entry into the elderly care market.

\section{Health}

Ageing brings significant changes to health status and needs. It affects both sensory (e.g., vision, hearing, and smell) and physical functions (e.g., motor ability), all of which may progress differently depending on medical condition (e.g., diabetes, arthritis, and multiple chronic illnesses) and individual habits (e.g., exercise, tobacco use, and diet) (Yoon, Cole and Lee, 2009).

The evidence behind health condition and planning is mixed at best (Scanlon, Chernew and Lave, 1997). Compared to people in poor health (e.g., chronic conditions), those in good health may value future losses to illnesses and health declines much more, and thus take precautionary measures by planning for such circumstances (e.g., gather information; buy health insurance) (Winter, Moss and Hoffman, 2009). On the other hand, people experiencing good health may suffer from an optimism bias such that they perceive their odds of falling ill and needing future care as much lower than someone in a state of health decline (Bränström, Kristjansson and Ullén, 2006; Ackerson and Preston, 2009). As such, good health can both motivate and constrain an individual's predisposition to care planning.

While the evidence behind health status and early planning remains mixed, we believe this is down to how people judge the severity of a potential health decline/issue, which Tversky and Kahneman (1981) explain is usually reference-dependent. For example, people in good health stand to "lose" more from severe illnesses and crises (e.g., life-changing accidents) than those who are already in poor health. Though we suspect losses to advance age may weigh heavier in the minds of younger, healthier, risk averse, and more image/self-esteem conscious individuals, there is little research in the area of social care to confirm this.

\section{Knowledge and awareness}

Knowledge on how the social care system works and the range of care options available, is a crucial step in informed decision making (NHS, 2018). With age, people normally gain more exposure to the 
care schemes available to them and develop better awareness on their own personal care needs.

Some triggering events could be programs and campaigns aimed at raising awareness on the importance of early care planning. This may include common media channels (e.g., news; social media; door-to-door letters), community or street campaigns, as well as seminars at a person's place of employment. In a randomised controlled trial, individuals assigned to receive advance care planning $^{2}$ were significantly more likely to get the end-of-life care they had planned for than those in the control group who received no formal training (Detering et al., 2010).

Elsewhere, studies show that individuals who attend financial preparation seminars at their workplace develop a more favourable attitude toward retirement, acquire more knowledge on basic financial planning, are more likely to engage in financial preparation (Adams and Rau, 2011) and contribute more to their personal retirement funding plans (Bayer, Bernheim and Scholz, 1996).

Conversely, poor accuracy in accumulated knowledge and poor levels of awareness can impede planning and decision making. A recent survey showed that many "have never heard of social care... do not understand what it is, what aspects of care it covers, how to access it..." (Mattinson and Knox, 2015). Furthermore, people often confuse health and social care, consult GPs for advice on care options instead of their local authority, and feel surprised by the need to pay for their potential care (Behavioural Insights Team, 2017; Which?, 2018).

Improving awareness and educating the public on social care is an urgent area to address, judging by current standards of knowledge in the population. While such interventions are likely to improve people's preparedness and ability to respond appropriately to crises, more direct evidence is needed to show that providing information alone motivates early planning in elderly care.

\section{Goals and motivation}

Reasoning (i.e., knowledge and awareness) alone may not compel individuals to plan for their care needs. Consumers who possess clear goals and strong motivation are more capable at overcoming possible psychological barriers and likely to take preparatory action to ensure they meet those ends. Studies suggest that individuals with goal clarity, a future time perspective (i.e., a preference for taking a long-term view as opposed to focusing on the past or present), and a long-term planning orientation are more likely to make financial preparation and contribute more towards their retirement (Jacobs-Lawson and Hershey, 2005; Stawski, Hershey and Jacobs-Lawson, 2007). There is, however, limited evidence on the prevalence of such characteristics, or if they predict planning and saving for social care in the UK.

The nature of consumer health and social care however, generally demotivates people from engaging matters associated with it. Unlike most consumer goods where purchases generate feelings of satisfaction and happiness, products in the care sector are frequently bought out of necessity. Most of these produce strong aversive feelings, which can cause psychological discomfort (Edgman-Levitan

$9 \quad{ }^{2}$ Trained facilitators assist patients and family members to discuss patients' goals, values, beliefs, and document their future care options. 
and Cleary, 1996). Interviews reveal that some consumers find home adaptations, such as handrails and ramps, as attempts to medicalise one's home (Powell et al., 2017). Others perceive 'help is needed' as a threat to their self-esteem and dignity (Which?, 2018). Because these issues are often offputting, consumers tend to avoid considering them in the first place. Design-thinking can help make home adaptations less obtrusive (e.g., option to hide/tuck away) or more aesthetically pleasing, such that they appear part of the modern landscape rather than something bought out of need.

\section{Sense of security}

Individuals, young or old, treasure a sense of security. By that, we mean people are likely to plan or act on issues that promote psychological safety and emotional wellbeing. The passing of a close one or spells of loneliness may trigger feelings of vulnerability, loss of control and anxiety (Age UK, 2018; Which?, 2018). Individuals who fear or experience these situations tend to desire more social interaction and make plans to quell this unsettling feeling (Bandura, 1977; Spielberger, 2010).

Conversely, people in smaller households may struggle and feel more vulnerable to potential crises than those in bigger households who have a larger support network to rely on. For example, data from the 2012 National Health Interview Survey showed that expectations about long-term services varied by current living arrangements such that respondents living alone were the most likely to expect the need for future long-term services and reliance on paid care (Henning-Smith and Shippee, 2015).

A sense of security can quickly prove false due to unexpected events, be it personal/individual (e.g., falls at home) or systemic (e.g. economic recession). While there is limited empirical evidence linking these factors to care planning in the UK, it is possible that poor levels of awareness, misconceptions that social care is free, and a false sense of security could explain low levels of planning in the UK. 


\title{
Task and contextual factors
}

\author{
Task-related and situational influences can hinder or facilitate the ease with which consumers \\ understand, plan and decide on a range of matters.
}

As much as it would benefit consumers to plan their care needs in advance, decision making is often subject to external influences that people have low or no control over. These normally relate to aspects of the decision task or the urgency of the situation. In addition, we acknowledge the important role external parties play in these issues.

\section{Familiarity}

The performance of certain everyday tasks can become so routine and repetitive that they require little or no conscious effort to execute. Over time, individuals may develop a mental script on how to execute them (e.g., daily travels to the local community centre), and mental schemas for categorizing, comprehending and generalizing issues (e.g., products from certain countries are of better quality) (Reyna and Brainerd, 1995). Familiarity may also help explain, in addition to having an established network of support, comfort, and independence, why people overwhelmingly prefer to stay comfortably at home and adjust if need be (e.g., domiciliary care; adaptations) than move into other types of sheltered care (Behavioural Insights Team, 2017).

On the other hand, consumers are likely to find the management of new, novel tasks, such as learning to navigate the complex care system for the first time, to be especially daunting and challenging for them. A recent study revealed that consumers frequently find new technological aids complicated to learn and use (Which?, 2018). Learning requires controlled, deliberative processes where prior knowledge is unlikely to help in a unique task or situation (Yoon, Cole and Lee, 2009).

Since planning for potential care needs is, by its very nature, unfamiliar and based on hypothetical expectations, individuals may not be able to express clear, coherent preferences before the onset of a crisis (Winter, Moss and Hoffman, 2009). Furthermore, consumer preferences and needs for care are likely to evolve with time, situation and exposure to a crisis (Which?, 2018). Visual simulations, visits to care homes and service excellence indicators may help consumers clarify their needs and expectations and form preliminary preferences of what it is they want in future.

\section{Urgency}

Presence of time pressure can have detrimental effects on the decision making abilities of people. Time pressure is especially relevant in the elderly care sector where decisions often arise from having 
to respond to immediate crises, as opposed to being part of a meticulous plan (Which?, 2018). In most cases, individuals will come under immense stress and pressure to decide quickly, without the luxury of considering all available information to make a good decision. Consumers for example, cannot request for local authority-funded home adaptations until they need one. In addition, these may arrive too late to be of much use due to a long waitlist (e.g., 12 months for a stairlift) (Croucher, 2008; Powell et al., 2017).

While an absence of time pressure is generally more conducive for rational decision making, a perceived lack of urgency can impede people from planning early. Researchers explain that people discount the importance or value of future choices at different rates, depending on individual age and preferences. Hershfield (2011) attributes this behaviour to a sense, or lack thereof, of a physiological connection to their future self. Other than placing one in a future state or condition, either by imagination or simulation, there is currently little understanding on what triggers such powerful physiological feelings that it overcomes motivational barriers to planning (Hershfield, 2011).

\section{Information and task complexity}

Characteristics of the decision environment can significantly influence the ease with which individuals learn, navigate and use information to make a good decision. Ill-conceived, these issues can feel more difficult, aversive, and off-putting to decision makers, the effects of which are likely to be stronger in an emotionally-charged context like elderly care (Edgman-Levitan and Cleary, 1996).

\section{Information overload}

It is implicitly assumed that consumers understand their health condition, the available options to them, and the consequences associated with these options to make an informed choice. There are several strategies to facilitate learning and maximise comprehension, including the use of nontechnical language/description, simple format and data (e.g., using absolute numbers instead of percentages), graphical representations (e.g., visual markers; colour coding), and enhancing interactivity (e.g., visiting potential care homes or sheltered housing). Samanez-Larkin, Wagner, and Knutson (2011) demonstrate that distracting information has a less pronounced effect on decision quality when experimenters display critical information in a simplified layout and format. Decision quality usually improves, including for those older in age.

On the other hand, complex and excessive information can trigger aversive reactions in people, enough to overwhelm and deter them from planning in the first place (Which?, 2018). A metaanalysis on age-related effects on information search and decision outcomes suggests that older adults generally consider fewer pieces of information before making a decision, attend to more positive than negatively-laden material (Shamaskin, Mikels and Reed, 2010), and rely on simpler decision strategies (e.g., rely on poor memory), which often leads to poorer decision outcomes (e.g., less profitable stocks) (Mata and Nunes, 2010). The authors note that large improvements in decision quality are unlikely to come from simply giving more information to older adults (Mata and Nunes, 2010). 


\section{Choice overload}

Contrary to popular belief, more is not always better when it comes to choice. Consistent research show that individuals encountering a large assortment of options (e.g., mobility aids; care homes) are less likely to make a choice at all or express satisfaction when compared against individuals with smaller choice sets - a phenomenon known as "choice overload". Some experts point to "anticipated regret" as an underlying factor. Faced with an excessively large array of choices, people usually feel more frustrated and less confident due to preference uncertainty and viewing other options as forgone opportunities (Iyengar and Lepper, 2000; Schwartz, 2004; Botti and Iyengar, 2006).

Moreover, there are cognitive and situational constraints (e.g., time) to how much information one can reasonably process (Mata et al., 2012). In the UK for example, several reports indicate that the number of care options to choose from can often be confusing, and increases stress and anxiety for fear of making a "wrong" choice (Umali, Case and Miller, 2016). Elsewhere, a roll out of forty or more Medicare coverage plans in the US reportedly overwhelms most people. Few seniors found such "choice" helpful and 73\% felt the plan was "difficult and confusing." (Kaiser Family Foundation, 2006).

We note that there are structural factors, such as geography, council budgets, and financial costs, influencing the availability of options to consumers. However, these issues are beyond the scope of this report and we believe do not explain why consumers plan early for their care needs in the first place.

As it relates to planning for potential care, having both more information and choice is, from a rational perspective, considered more desirable than having less. However, the appropriate amount will tend to depend on individuals' cognitive abilities, motivations and health circumstances. There are two key areas for improvement in this regard: 1) clear signposting and navigational tools can help consumers get the right information they want, at the right time they need; and 2) an option to customize the 'right' amount of information and choice to mitigate unnecessary stress, and facilitate informed decision making.

These suggestions, along with those mentioned under "Familiarity," are some general strategies for improving access to information and facilitating deliberation. Despite this, more research is needed to establish the relative effectiveness of these interventions in promoting early care planning.

\section{Shared decision making}

Unpaid carers (e.g., friends, neighbours, family) and service providers (e.g., social workers, local authorities) play an increasingly active role in the provision of social care. These parties can share in decision making (e.g., reduce information and choice overload) and/or contribute directly to satisfaction by meeting elderly care needs (e.g., emotional and physical wellbeing). Shared decision making is a collaborative process in which consumers and providers make informed decisions, based on an individuals' preferences (Makoul and Clayman, 2006). It happens when consumers interact with their local authorities or family members to make complex care plans. 


\section{Unpaid carers}

According to the Department for Work and Pensions (2017), about 8\% of the UK's private household population were "informal carers" for someone, contributing about $£ 57$ billion worth of social care from 2016 to 2017 . When adults reach 50, women were likely to spend approximately 5.9 years, and males approximately 4.9 years of their remaining life as unpaid carers (Office for National Statistics, 2017).

Unpaid carers are usually close acquaintances who know a lot about the needs and preferences of those they care for. They are aptly suited to share in decision making and provide support in a range of scenarios. There is also evidence to suggest that compared to those who receive usual care, people and family members who undergo training in advance care planning, before a loss of mental functioning, report significantly higher satisfaction with their end of life care. It also lowers anxiety, stress and depression levels in family members of those who have passed away (Detering et al., 2010).

Despite the growing importance with which unpaid carers play in maintaining and meeting the needs of closed ones, there is no direct evidence to suggest that having an additional decision maker (as opposed to the consumer alone) increases the likelihood of early planning in elderly care. More work is needed to understand the contributions unpaid carers make in elderly care planning.

\section{Service providers}

There is a general recognition that personalisation is desirable in social care, and organizations have taken measures to ensure they respect and respond to individuals' preferences. The Care Quality Commission (2017) suggests the following: (1) tailoring activities to individuals' likes and interests; (2) supportive staff that actively encourage wide community engagement; and (3) arranging the environment to promote positive, learning and social experiences. The Shared Lives service is one good example of how shared decision making can enhance satisfaction. It is a recent programme aimed at matching adults with specific care needs to carers with the appropriate skill set, where over 90\% rated the service as good or outstanding (Care Quality Commission, 2017).

There is however, much to improve on when it comes to meeting the needs of older people. The 2017 ASCS puts overall satisfaction among service users at 64.7 percent (NHS, 2017). A recent survey of care home users conducted by Which? showed that 53 percent had experienced a negative issue and 41 percent were dissatisfied with their complaint outcome. In relation to choice provision, only 67.6 percent reported as having sufficient choice over the services they receive, while 6.3 percent did not want or need choice (NHS, 2017). Likewise, a survey by Which? indicated that 42 percent of home care users felt they had no control over the care they receive. In addition, care consumers desire more social interaction. The 2017 ASCS survey found that only 45.4 percent of service users had as much social contact as they would like (NHS, 2017).

In general, shared decision making is an influential approach for helping and motivating people to receive the care they want. Though the importance of carers and local authorities in providing social care is likely to increase in the coming years, there is little understanding on the specific ways in 
which they contribute to consumer planning and if these are necessary for them to make good decisions. 


\section{Cognitive and emotional factors}

\section{Individual and situational factors interact to influence the process by which care consumers make their decisions.}

Heuristics, biases and emotional reactions influence how individuals process information and come to an informed decision.

\section{Heuristics and biases}

Decision scientists and behavioural economists document a host of cognitive biases and heuristics (i.e., mental shortcuts) that affect judgment and decision in relation to elderly care (Behavioural Insights Team, 2017). When people make decisions, they often rely on mental shortcuts and intuition, rather than systematic deliberation, which may give way to cognitive biases (i.e., systematic errors in judgment). For example, people tend to choose what others choose (i.e., bandwagon effect), to go with a preselected option (i.e., default bias), believe they are at a lower risk of experiencing a negative event than others (i.e., optimism bias), and judge the likelihood of an event based on readily recallable examples (i.e., availability bias) (Blumenthal-Barby and Krieger, 2015).

These issues can affect how people judge and plan their potential care needs. An optimism bias may cause people to underestimate the probability of a negative event, such as moving into a care home or installing obtrusive handrails. Alternatively, negative news surrounding the state of social care can have a disproportionate effect on people's memory and perception of care homes - for example, consumers who develop an availability bias may read bad press about poor quality in one aspect of the care system, but incorrectly apply that assumption to all other types of care. In both cases, individuals are unlikely to consider all information and make good plans for their potential future care needs.

Furthermore, ageing appears to trigger negative stereotypes in people; it can shape how people think and interact with these individuals, as well as how those within the stereotyped group see themselves (Dionigi, 2015). Stereotypes of ageing in most Western cultures are primarily negative, depicting later life as a period of ill health, loneliness, and mental and physical decline. While stereotypes of ageing can also be positive (e.g., wealthy; wise), it is important to note the diversity with which people respond to the concept of ageing (for a review, see Dionigi [2015]).

One theory posits that people find ageing a threatening process. To elaborate, people exposed to ageing-associated triggers (e.g., sickness; helplessness; dependence) often report greater anxiety, blood pressure, fear of being perceived as sick and lower will-to-live. Auman et al. (2005) argue that ageing triggers fears of frailty and illness, and discourages people from seeking medical attention. Similarly, Levy et al. (2000) showed that activating negative ageing stereotypes in older adults reduced their likelihood of choosing care options that would prolong their life. 
A possible way to combat the perceived threat of ageing is to grant people greater perceived control over the situation. Improving people's autonomy in personal care decisions, supporting people in developing their own plans for their potential future care and motivating them to seek out preventive care measures are some possible ways of achieving this (Scholl and Sabat, 2008).

\section{Emotion}

Emotion has motivational properties when it comes to care planning, and we list three ways in which it can influence this.

\section{Affective forecasting}

Consumers facing decisions that will impact quality of life make assumptions about how well they can adapt emotionally to living with declines in health condition and physical functioning. However, people are generally poor at predicting their future emotional state and their ability to overcome adversity, a common phenomenon known as affective forecasting (Winter, Moss and Hoffman, 2009). For example, people usually focus on what will change or deteriorate (e.g., growing frail and dying) rather than on what will stay the same (e.g., ageing is a natural process) or even improve (e.g., more personal time and freedom), which explains why people avoid engaging such thoughts in the first place (Which?, 2018). Similarly, consumers fear home adaptations will devalue their home (Croucher, 2008), even when most prefer to stay than move away anyway (Behavioural Insights Team, 2017). It can also account for the general resistance people have towards home adaptations.

\section{Hot-cold emotional gap}

People are generally poor at predicting their ability to control visceral forces (e.g., anxiety; uncertainty; sadness; guilt) that may influence behaviour and preferences, especially how they transcend across 'hot-cold' emotional states (Loewenstein, 2005). Whereas people in a 'cold' state frequently fail to fully and accurately appreciate how 'hot' states will affect their behaviour and preferences, people in a 'hot' state tend to overestimate their ability to manage and control such influences. In the care sector, physical discomfort (e.g., pain), crises and emotionally-charged states (e.g., anxiety) normally contribute to more impulsive behaviours, including choices which they may not have made if given more time and support (Behavioural Insights Team, 2017). Conversely, planning usually happens in a 'cold' state and consumers may delay critical decisions, such as checking out possible care homes and making arrangement to live closer to close ones, thinking they can cope with crises as they come (Croucher, 2008).

\section{Social interactions}

Emotion has interpersonal implications as well. Feelings of anxiety and distress are known to increase perceptions of vulnerability, and lower individuals' self-efficacy and confidence levels to confront and overcome challenges (Bandura, 1977; Santana and Fontenelle, 2011). It also triggers a greater need for social interaction and inclusion to help combat uncertainty (Bandura, 1977; Santana and Fontenelle, 2011). With these in mind, Gino and colleagues (2012) showed that individuals induced to feel anxiety were more likely to seek and rely on advice, and were less discerning between good and 
bad advice. For example, qualitative research indicate that people want a caring relationship where they feel supported and in control of their own services (Which?, 2018).

Cognitive and emotional influences are inherent aspects of decision making. Compared to research on the first two chapters (i.e., individual factors; task and contextual factors), there is significantly lesser understanding on the prevalence and specific ways in which biases and emotion influence social care planning. This said, interventions targeting the first two areas are likely to bring improvements to cognition and emotional functioning, because most experts see decision making as a consequence of how individual factors interact with task characteristics (Tversky and Kahneman, 1973; Kahneman, 2003; Thaler and Sunstein, 2008). For example, poor knowledge and awareness on how the social care system works, coupled with having to respond to an emergency (e.g., a fall), can significantly exacerbate the influence which heuristics, biases, and emotions have in shaping care decisions and plans. These often have undesirable consequences for making good decisions and plans. We therefore suggest a multi-pronged approach, focusing on individual and contextual factors, and then studying how such interventions improve cognitive and emotional aspects in decision making. 


\section{Conclusions}

Planning and decision making in social care is a complex and multifaceted affair. It involves individual, task/contextual, cognitive and emotional issues that can either impede or help people receive the care they want. In some cases, they may influence the ease and process by which one plans for future care. On other occasions, they may provide functional and relational support, and thus contribute directly to the experience of care itself.

In addition, our review finds that empirical academic evidence on elderly care decision making is generally few and far between. As such, our findings often draws its insights from other closely linked domains, such as financial/retirement planning, healthcare-related decisions, and general psychology. To contribute knowledge on this emerging area of importance, we suggest the following experiments:

- A nationally representative study to understand the factors that predict elderly care planning

- A study among current elderly care users to understand how and why they entered the elderly care market, as well as if and how shared decision making played in this process.

- A study among prospective elderly care users on how different shared decision making designs (e.g., decision aids; expert/peer recommendations) can facilitate early planning.

We conclude by highlighting five critical pinch points that are likely to improve decision making in social care:

- Preferences. Individuals rarely possess clear, coherent preferences over what their future care needs may be. Moreover, asking consumers to envision these in a future state of health and physical decline can be challenging for them. Learning from others' experience (e.g., reviews; personal stories) can be a good way for consumers to understand what it is they want and how best to plan for them.

- Awareness. Most consumers are unaware of even the basics of social care; that it is different from the NHS and not always free for them. Hence, poor levels of care planning in the UK at present may be due to poor knowledge over the need to save and prepare oneself. Nevertheless, it is difficult to say if awareness alone will necessarily prompt early planning, as preferences to delay and discount future care are likely to persist.

- Information and choice provision. When consumers do decide to plan their future care, it is highly critical that information and choice is organized in a manner that facilitates comprehension and decision making. Decision aids and tools that allow one to customize the number of options to view and features to consider can reduce complexity. Pictures, simulations, clearly labelled prices, accessibility symbols, customer satisfaction stars and reviews, and even industry accreditation (e.g., Which? Recommended) can help improve decision making.

- Network support. While carers and local authorities play an important role in care planning, 
how and in what ways they contribute to good decisions remain relatively unclear. Given that consumers rarely make such important decisions about their future alone, their involvement is likely to have a strong influence on self-reported satisfaction and experiences of care.

- Stigma. Caregivers and consumers may benefit from a new approach to elderly life by framing ageing as a natural process that people eventually grow into, rather than something to fear. Likewise, design-thinking can help obtrusive home adaptations (e.g., handrails) blend in more naturally with modern home landscapes, without compromising safety. 


\section{References}

Ackerson, K. and Preston, S. D. (2009) 'A decision theory perspective on why women do or do not decide to have cancer screening: systematic review', Journal of Advanced Nursing. Wiley/Blackwell (10.1111), 65(6), pp. 1130-1140. doi: 10.1111/j.1365-2648.2009.04981.x.

Adams, G. A. and Rau, B. L. (2011) 'Putting off tomorrow to do what you want today: Planning for retirement.', American Psychologist, 66(3), pp. 180-192. doi: 10.1037/a0022131.

Age UK (2018) Struggling to cope, Policy and research. Available at: https://www.ageuk.org.uk/ourimpact/policy-research/struggling-to-cope/ (Accessed: 5 June 2018).

Auman, C., Bosworth, H. B. and Hess, T. M. (2005) 'Effect of health-related stereotypes on physiological responses of hypertensive middle-aged and older men', Journals of Gerontology -

Series B Psychological Sciences and Social Sciences, 60(1), pp. 3-10. doi: 10.1093/geronb/60.1.P3. Bandura, A. (1977) 'Self-efficacy: toward a unifying theory of behavioral change.', Psychological review, 84(2), pp. 191-215.

Bayer, P., Bernheim, B. D. and Scholz, J. K. (1996) The Effects of Financial Education in the Workplace: Evidence from a Survey of Employers. Cambridge, MA. doi: 10.3386/w5655.

Behavioural Insights Team (2017) Helping people make better decisions in the care home market. Available at: https://assets.publishing.service.gov.uk/media/5a1fd914ed915d458b922ec0/bit-cmacare-home-market-report.pdf.

Blumenthal-Barby, J. S. and Krieger, H. (2015) 'Cognitive biases and heuristics in medical decision making: a critical review using a systematic search strategy.', Medical Decision Making, 35(4), pp. 539-557. doi: 10.1177/0272989X14547740.

Botti, S. and Iyengar, S. S. (2006) 'The Dark Side of Choice: When Choice Impairs Social Welfare', Journal of Public Policy \& Marketing, 25(1), pp. 24-38. doi: 10.1509/jppm.25.1.24.

Bränström, R., Kristjansson, S. and Ullén, H. (2006) 'Risk perception, optimistic bias, and readiness to change sun related behaviour', European Journal of Public Health. Oxford University Press, 16(5), pp. 492-497. doi: 10.1093/eurpub/cki193.

Care Quality Commission (2017) The state of health care and adult social care in England 2016/2017, State of Care. Available at: http://www.cqc.org.uk/publications/major-report/state-care. Croucher, K. (2008) Housing Choices and Aspirations of Older People, Communities and Local Government.

Department for Work and Pensions (2017) Family resources survey 2016/17, Family Resources Survey. Available at:

https://assets.publishing.service.gov.uk/government/uploads/system/uploads/attachment_data/file/692 771/family-resources-survey-2016-17.pdf.

Department of health and social care (2014) Care Act factsheets - GOV.UK, Personal Social Services Adult Social Care Survey. Available at: https://www.gov.uk/government/publications/care-act-2014part-1-factsheets/care-act-factsheets\#factsheet-1-general-responsibilities-of-local-authoritiesprevention-information-and-advice-and-shaping-the-market-of-care-and-support-services (Accessed: 17 May 2018).

Detering, K. M. et al. (2010) 'The impact of advance care planning on end of life care in elderly patients: randomised controlled trial', BMJ. British Medical Journal Publishing Group, 340, p. c1345. doi: $10.1136 / \mathrm{bmj} . c 1345$.

Dionigi, R. A. (2015) 'Stereotypes of Aging: Their Effects on the Health of Older Adults', Journal of Geriatrics. Hindawi, 2015, pp. 1-9. doi: 10.1155/2015/954027.

Edgman-Levitan, S. and Cleary, P. D. (1996) 'What Information Do Consumers Want and Need?',

21 Health Affairs. Project HOPE - The People-to-People Health Foundation, Inc. , 15(4), pp. 42-56. doi: 10.1377/hlthaff.15.4.42. 
Gino, F., Brooks, A. W. and Schweitzer, M. E. (2012) 'Anxiety, advice, and the ability to discern: Feeling anxious motivates individuals to seek and use advice', Journal of Personality and Social Psychology, 102(3), pp. 497-512. doi: 10.1037/a0026413.

Henning-Smith, C. E. and Shippee, T. P. (2015) 'Expectations about future use of long-term services and supports vary by current living arrangement', Health Affairs, 34(1), pp. 39-47. doi:

10.1377/hlthaff.2014.0556.

Hershfield, H. E. (2011) 'Future self-continuity: how conceptions of the future self transform intertemporal choice.', Annals of the New York Academy of Sciences. NIH Public Access, 1235, pp. 30-43. doi: 10.1111/j.1749-6632.2011.06201.x.

Ipsos MORI (2017) Public perceptions of austerity, social care and personal data, The State of the State 2017-18. Available at: https://www.ipsos.com/ipsos-mori/en-uk/public-perceptions-austeritysocial-care-and-personal-data (Accessed: 6 June 2018).

Iyengar, S. S. and Lepper, M. R. (2000) 'When Choice is Demotivating: Can One Desire Too Much of a Good Thing?', Journal of Personality and Social Psychology. Journal of Personality and Social Psychology, 79(6), pp. 995-1006.

Jacobs-Lawson, J. M. and Hershey, D. A. (2005) 'Influence of future time perspective, financial knowledge, and financial risk tolerance on retirement saving behaviors', Financial Service Review, 14(4), pp. 331-344.

Kahneman, D. (2003) 'A perspective on judgment and choice: mapping bounded rationality.', The American Psychologist, 58(9), pp. 697-720. doi: 10.1037/0003-066X.58.9.697.

Kaiser Family Foundation (2006) Kaiser Health Poll Report Survey - Selected Findings on Seniors' Views of the Medicare Prescription Drug Benefit, Kaiser Health Poll Report. Available at: https://www.kff.org/medicare/poll-finding/kaiser-health-poll-report-survey-selected-findings/ (Accessed: 17 May 2018).

Levy, B., Ashman, O. and Dror, I. (2000) 'To be of not to be: The effects of aging stereotypes on the will to live', OMEGA, 40(3), pp. 409-420.

Loewenstein, G. (2005) 'Hot-Cold Empathy Gaps and Medical Decision Making.', Health Psychology. American Psychological Association, 24(4, Suppl), pp. S49-S56. doi: 10.1037/02786133.24.4.S49.

Lusardi, A. and Mitchelli, O. S. (2007) 'Financial Literacy and Retirement Preparedness: Evidence and Implications for Financial Education', Business Economics, 42(1), pp. 35-44. doi:

$10.2145 / 20070104$.

Makoul, G. and Clayman, M. L. (2006) 'An integrative model of shared decision making in medical encounters.', Patient Education \& Counseling, 60(3), pp. 301-312. doi: 10.1016/j.pec.2005.06.010. Mata, R. et al. (2012) 'Ecological Rationality: A Framework for Understanding and Aiding the Aging Decision Maker', Frontiers in Neuroscience. Frontiers, 6, p. 19. doi: 10.3389/fnins.2012.00019. Mata, R. and Nunes, L. (2010) 'When Less Is Enough: Cognitive Aging, Information Search, and Decision Quality in Consumer Choice', Psychology and aging, 25(2), pp. 289-298. doi: 10.1037/a0017927.

Mattinson, D. and Knox, A. (2015) An ageing Britain don't know what social care is - time for a rebrand, Britain Thinks. Available at: http://www.slackcommunications.co.uk/an-ageing-britain-dontknow-what-social-care-is-time-for-a-rebrand-says-britainthinks/ (Accessed: 17 May 2018).

Mullick, A., Martin, J. and Sallnow, L. (2013) 'An introduction to advance care planning in practice', $B M J, 347$, p. f6064. doi: 10.1136/bmj.f6064.

NHS (2017) Personal Social Services Adult Social Care Survey, England 2016-17, Personal Social Services Adult Social Care Survey. Available at: https://digital.nhs.uk/data-and-

information/publications/statistical/personal-social-services-adult-social-care-survey/personal-socialservices-adult-social-care-survey-england-2016-17 (Accessed: 17 May 2018).

NHS (2018) Planning for your future care needs. Available at: https://www.nhs.uk/conditions/socialcare-and-support/planning-for-your-future-care-needs/ (Accessed: 17 May 2018). 
Office for National Statistics (2017) Unpaid carers provide social care worth $£ 57$ billion - Office for National Statistics, Health and life expectancies. Available at:

https://www.ons.gov.uk/peoplepopulationandcommunity/healthandsocialcare/healthandlifeexpectanci es/articles/unpaidcarersprovidesocialcareworth57billion/2017-07-10 (Accessed: 17 May 2018).

Powell, J. et al. (2017) The role of home adaptations in improving later life.

Reyna, V. F. and Brainerd, C. J. (1995) 'Fuzzy-trace theory: An interim synthesis', Learning and Individual Differences. JAI, 7(1), pp. 1-75. doi: 10.1016/1041-6080(95)90031-4.

Samanez-Larkin, G. R., Wagner, A. D. and Knutson, B. (2011) 'Expected value information improves financial risk taking across the adult life span.', Social cognitive and affective neuroscience. Oxford University Press, 6(2), pp. 207-17. doi: 10.1093/scan/nsq043.

Santana, L. and Fontenelle, L. F. (2011) 'A review of studies concerning treatment adherence of patients with anxiety disorders', Patient Preference and Adherence, pp. 5-427. doi:

10.2147/PPA.S23439.

Scanlon, D. P., Chernew, M. and Lave, J. R. (1997) 'Consumer health plan choice: current knowledge and future directions.', Annual review of public health, 18, pp. 507-28. doi:

10.1146/annurev.publhealth.18.1.507.

Scholl, J. M. and Sabat, S. R. (2008) 'Stereotypes, stereotype threat and ageing: Implications for the understanding and treatment of people with Alzheimer's disease', Ageing and Society, 28(1), pp. 103130. doi: $10.1017 / \mathrm{S} 0144686 \mathrm{X} 07006241$.

Schwartz, B. (2004) 'The Tyranny of Choice', Scientific American. Scientific American, a division of Nature America, Inc., pp. 70-75. doi: 10.2307/26047678.

Shamaskin, A. M., Mikels, J. A. and Reed, A. E. (2010) 'Getting the message across: Age differences in the positive and negative framing of health care messages.', Psychology and Aging, 25(3), pp. 746751. doi: $10.1037 / \mathrm{a} 0018431$.

Spielberger, C. D. (2010) 'State-Trait Anxiety Inventory', in The Corsini Encyclopedia of Psychology. Hoboken, NJ, USA: John Wiley \& Sons, Inc. doi: 10.1002/9780470479216.corpsy0943.

Stawski, R. S., Hershey, D. A. and Jacobs-Lawson, J. M. (2007) 'Goal Clarity and Financial Planning Activities as Determinants of Retirement Savings Contributions', The International Journal of Aging and Human Development, 64(1), pp. 13-32. doi: 10.2190/13GK-5H72-H324-16P2.

Thaler, R. H. and Sunstein, C. R. (2008) Nudge: Improving Decisions About Health, Wealth and Happiness. Yale University Press.

Tversky, A. and Kahneman, D. (1973) 'Availability: A heuristic for judging frequency and probability', Cognitive Psychology. Elsevier Science, 5(2), pp. 207-232. doi: 10.1016/00100285(73)90033-9.

Tversky, A. and Kahneman, D. (1981) 'The framing of decisions and the psychology of choice.', Science, 211(4481), pp. 453-458. doi: 10.1126/science.7455683.

Umali, G., Case, R. and Miller, B. (2016) Older people are paying the price for cuts to social care, The King's Fund. Available at: https://www.kingsfund.org.uk/press/press-releases/older-peoplesocial-care-cuts (Accessed: 18 May 2018).

Which? (2018) Social care for older people.

Winter, L., Moss, M. S. and Hoffman, C. (2009) 'Affective forecasting and advance care planning: Anticipating quality of life in future health statuses', Journal of Health Psychology, 14(3), pp. 447456. doi: 10.1177/1359105309102201.

Yoon, C., Cole, C. A. and Lee, M. P. (2009) 'Consumer decision making and aging: Current knowledge and future directions', Journal of Consumer Psychology, 19(1), pp. 2-16. doi:

10.1016/j.jcps.2008.12.002. 